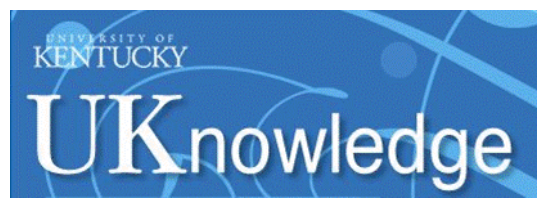

University of Kentucky

UKnowledge

\title{
Racial and Ethnic Disparities in Stroke Outcomes: A Scoping Review of Post-Stroke Disability Assessment Tools
}

\author{
Suzanne Perea Burns \\ Medical University of South Carolina \\ Brandi M. White \\ University of Kentucky, brandi.white50@uky.edu \\ Gayenell Magwood \\ Medical University of South Carolina \\ Charles Ellis \\ East Carolina University \\ Ayaba Logan \\ Medical University of South Carolina
}

See next page for additional authors

Follow this and additional works at: https://uknowledge.uky.edu/clinicalsci_facpub

Part of the Race and Ethnicity Commons, and the Rehabilitation and Therapy Commons

Right click to open a feedback form in a new tab to let us know how this document benefits you.

\section{Repository Citation}

Burns, Suzanne Perea; White, Brandi M.; Magwood, Gayenell; Ellis, Charles; Logan, Ayaba; Jones Buie, Joy N.; and Adams, Robert J., "Racial and Ethnic Disparities in Stroke Outcomes: A Scoping Review of PostStroke Disability Assessment Tools" (2019). Health and Clinical Sciences Faculty Publications. 14. https://uknowledge.uky.edu/clinicalsci_facpub/14

This Review is brought to you for free and open access by the Health and Clinical Sciences at UKnowledge. It has been accepted for inclusion in Health and Clinical Sciences Faculty Publications by an authorized administrator of UKnowledge. For more information, please contact UKnowledge@lsv.uky.edu. 


\section{Racial and Ethnic Disparities in Stroke Outcomes: A Scoping Review of Post- Stroke Disability Assessment Tools}

Digital Object Identifier (DOI)

https://doi.org/10.1080/09638288.2018.1448467

\section{Notes/Citation Information}

Published in Disability and Rehabilitation, v. 41, issue 15, p. 1835-1845.

The copyright holder has granted the permission for posting the article here.

This is an Accepted Manuscript of an article published by Taylor \& Francis in Disability and Rehabilitation on July 2019, available online: http://www.tandfonline.com/10.1080/09638288.2018.1448467.

\section{Authors}

Suzanne Perea Burns, Brandi M. White, Gayenell Magwood, Charles Ellis, Ayaba Logan, Joy N. Jones Buie, and Robert J. Adams 


\title{
Racial and ethnic disparities in stroke outcomes: a scoping review of post-stroke disability assessment tools
}

\author{
Suzanne Perea Burns ${ }^{a}$, Brandi M. White ${ }^{b}$, Gayenell Magwood ${ }^{\mathrm{a}, \mathrm{c}}$, Charles Ellis ${ }^{\mathrm{d}}$, Ayaba \\ Logan $^{e}$, Joy N. Jones Buie ${ }^{a}$, Robert J. Adams ${ }^{a, f}$ \\ aWISSDOM Center, Medical University of South Carolina, Charleston, SC, USA; \\ bCollege of Health Sciences, University of Kentucky, Lexington, KY, USA; \\ 'College of Nursing, Medical University of South Carolina, Charleston, SC, USA; \\ ${ }^{d}$ Department of Communication Sciences and Disorders, East Carolina University, Greenville, NC, \\ USA; \\ eDepartment of Library Science and Informatics, Medical University of South Carolina, \\ Charleston, SC, USA; \\ fDepartment of Neurology, Medical University of South Carolina, Charleston, SC, USA
}

\section{Abstract}

Purpose: To identify how post-stroke disability outcomes are assessed in studies that examine racial/ethnic disparities and to map the identified assessment content to the International Classification of Functioning, Disability, and Health (ICF) across the time course of stroke recovery.

Methods: We conducted a scoping review of the literature. Articles published between January 2001 and July 2017 were identified through Scopus, PubMed, CINAHL, and PsycINFO according to predefined inclusion and exclusion criteria.

Results: We identified 1791 articles through database and hand-searching strategies. Of the articles, 194 met inclusion criteria for full-text review, and 41 met inclusion criteria for study inclusion. The included studies used a variety of outcome measures encompassing domains within the ICF: body functions, activities, participation, and contextual factors across the time course of stroke recovery. We discovered disproportionate representation among racial/ethnic groups in the post-stroke disability disparities literature.

Conclusions: A wide variety of assessments are used to examine disparities in post-stroke disability across the time course of stroke recovery. Several studies have identified disparities through a variety of assessments; however, substantial problems abound from the assessments used including inconsistent use of assessments, lacking evidence on the validity of assessments

CONTACT Suzanne Perea Burns sburns@twu.edu WISSDOM Center, Medical University of South Carolina, 99 Jonathan Lucas, Suite 508, MSC 160, Charleston, SC 29425, USA.

Disclosure statement

Authors have disclosed those interests fully to Taylor \& Francis and have in place an approved plan for managing any conflicts arising from the AHA grant. 
among racial/ethnic groups, and inadequate representation among all racial/ethnic populations comprising the US.

\section{Keywords}

Stroke; disability evaluation; health status disparity; minority health; patient outcome assessment

\section{Introduction}

Stroke is considered a chronic health condition that contributes to persistent and unmet longterm needs in the context of the community [1,2]. Adults with stroke often experience residual disability, participation limitations, and a range of personal, social, and economic hardships [3]. Recent evidence suggests that racial and ethnic minorities in the United States (US) are disproportionately affected by stroke and have a greater burden of post-stroke disability across the time course of stroke recovery (i.e., pre-stroke, acute, early recovery, long-term/community) [4-8]. Although a majority of studies have discovered disparities in stroke recovery outcomes among racial/ethnic minorities, inconsistencies in the findings exist. Variation in tools used to examine disparities in post-stroke disability may contribute to the inconsistent findings reported in the literature. For instance, studies that examine disparities in activity limitations across the time course of stroke recovery have demonstrated conflicting findings. Burgess et al. [8] describe how disparities in activity limitations measured by two different tools, the Barthel Index and modified Rankin Scale, have shown a range of findings (i.e., worse outcome, better outcome, and no difference in outcome) in racial minorities compared to non-Hispanic whites when examining short- and long-term outcomes.

Post-stroke functioning and disability is variable, complex, and may be influenced by residual impairments and a range of personal and contextual factors [9]. The World Health Organization's International Classification of Functioning, Disability, and Health (ICF) [10] is an internationally accepted framework that provides a common language for individual and population-level disability and functioning across the lifespan (Figure 1). The ICF aids in the conceptualization of interactions between functioning, activities, participation, and contextual influences (i.e., personal and environmental) pertaining to post-stroke disability [9]. The framework is built upon the International Classification of Impairments, Disability, and Handicaps (ICIDH) [11] which applied different basic principles and terminology but had similar aims. For instance, the ICIDH used impairment, disability, and handicap terminology which are referred to as body functions and structures, activities, and participation in the ICF, respectively. Additionally, the ICF introduced environmental factors that comprise the physical, social, and attitudinal environment [12]. Herein, we applied the ICF to review the literature on assessments used to examine disparities in post-stroke disability among a variety of racial/ethnic minority groups residing in the US.

When studying assessments used to examine disability among persons with stroke, it is inherently useful to work within a framework to categorize and classify data [13]. The ICF components correspond with functional outcome measures used in stroke recovery research and may be particularly useful in understanding disparities in functioning and disability. 
Furthermore, understanding the variability in assessments used to examine disparities in post-stroke disability throughout the literature may provide insight on the validity of reported disparities. The objectives of this review are three-fold: (1) identify assessments used in racial/ethnic disparities in post-stroke disability literature, (2) use the ICF as a frame of reference for mapping the contents of the identified measures, and (3) evaluate the time points of measured outcomes and racial/ethnic representation within the identified studies.

\section{Methods}

\section{Search strategy}

A scoping review of the literature was conducted to identify assessments that address domains of the ICF to examine racial/ethnic disparities in the US. We conducted a scoping review because it is useful in mapping fundamental concepts and identifying gaps in the literature by systematically examining, selecting, and integrating existing research [14]. The lead author and the research librarian conducted the initial search within PubMed, Scopus, CINAHL, and PsycINFO, and included the following terms MeSH and natural language terms: stroke, cerebral vascular disease, transient ischemic attack, outcome, outcome measure, outcome assessment, evaluation studies, impact, recovery, rehabilitation, restore, regain, resume, continental population groups, population, race, ethnology, ethnic groups, African American, Hispanic American, Latino/a, Mexican American, American Indian, Native American, Alaskan Native, Asian, ancestry, Pacific Islander, Native Hawaiian, people of color, black.

First, titles and abstracts were reviewed for inclusion for full-text review. Two authors independently reviewed the articles for inclusion and exclusion for data extraction. The authors also engaged in hand-searching which involved searching reference lists of included manuscripts and review articles, first author names of included studies, and search with terminology in Google Scholar. A dichotomous 'no' or 'maybe' scoring system for article inclusion was used. When reviewer disagreement on inclusion occurred, they convened to discuss and reach a consensus on inclusion. Abstracts that did not explicitly state the specific outcome measures used were reviewed during the full-text review.

\section{Inclusion and exclusion criteria}

Inclusion criteria consisted of the following items: (1) empirical research studies, (2) participants reported therein were aged 18 years or older, (3) objectives therein were to examine disparities in functional outcomes, and (4) studies were published between January 2001 and July 2017. Exclusion criteria for publications consisted of the following items: (1) did not exclusively focus on stroke, (2) did not focus on racial/ethnic disparities, (3) were not conducted at least partially in a US population, (4) described instrument development or psychometric analysis only, (5) did not report outcomes related to disability and functioning, (6) were not in English language, (7) focused on the stroke caregiver only, (8) ICD-9 codes as outcome or disability measure, and/or (9) were dissertation, commentary, blogs, conference proceedings, book chapters, case-studies, predictive modeling, or not comparative in focus. If literature reviews emerged in our search, we examined the reference list, located the publications, and screened for inclusion. Articles published prior to 2001 
were excluded because the ICF was published in this year and we expect it had a substantial impact on how disability and functioning are assessed in the literature. Finally, only published articles that compared outcomes among racial/ethnic groups were included. We did not include studies that used predictive modeling unless the articles also reported differences between groups.

\section{Data extraction and classification}

Once all of the publications that met inclusion criteria were identified, we extracted and recorded relevant information that matched the aims of this study: outcome measures used, assessment content type, racial/ethnic representation, and time points across the time course of stroke recovery when outcomes were assessed. The contents of outcome measures used within the identified studies were extracted and classified using the ICF browser (http:// apps.who.int/classifications/icfbrowser/). Race/ethnicity were categorized using minimum designations for race and ethnicity $[15,16]$. Time points for assessment across the time course of stroke recovery were broadly classified using pre-stroke, acute stroke (including hospitalization and rehabilitation), early recovery, and community living/long-term outcomes terminology as described by Skolarus and Burke [17]. For purposes of this study, early recovery outcomes included assessments administered $₫ 90$ days since the stroke. Additionally, if the studies used repeated measures for multiple points in time, we collected this information and categorized within both time points.

\section{Results}

\section{Literature search}

We identified 1791 articles through database and hand-searching strategies. One hundred and ninety-four articles met inclusion criteria for full-text review, and 41 met inclusion criteria after full-text review. Refer to Figure 2 for detailed depiction of inclusion and exclusion criteria application.

\section{Outcome measures}

The 41 included studies used a variety of assessments encompassing domains within the ICF: body functions, activities, participation, and contextual factors (Table 1). Two activity measures were the most frequently used: Functional Independence Measure (FIM) and modified Rankin Scale (mRS). Several studies used survey data from national data sources (e.g., National Health Interview Survey, Health and Retirement Study) that included selfreport questions about difficulty and capacity with body functions, activities, and participation. Additionally, two assessments used in the identified studies examined contextual factors. The majority of the assessments identified were only used by a single study.

\section{Assessment across the time course of stroke recovery}

Assessments for examining disparities in post-stroke disability were assessed across the time course of stroke recovery. The assessments were used at all pre-identified time points: prestroke $(n=9)$, acute stroke $(n=10)$, early recovery $(n=14)$, community living/long-term $(n$ $=33$ ). Some studies used repeated outcomes at more than one time point across the time 
course of stroke recovery and this information was collected and reported in Table 1. A majority of studies examined racial/ethnic disparities during community living/long-term with national data set and survey methodology. Refer to Figure 3.

\section{Racial/ethnic representation}

The included studies were comprised of four primary racial/ethnic groups: white $(n=41)$, black or African American $(n=36)$, Hispanic or Latino $(n=16)$, and Asian $(n=6)$.

Although the category of 'other' was used for several studies, few articles described the racial/ethnic representation in categories labeled as 'other'. We only factored participants described within the 'other' categories when the study itself delineated the composition.

Only one study in our review described the 'other' as being comprised of American Indian or Alaska Native and Native Hawaiian or Pacific Islander (Figure 4).

\section{Discussion}

A large number of outcome measures with a varied nature exist to support the assessment of disability and functioning across the time course of stroke recovery. The ICF presents a conceptual framework to convey the interactive effects that contribute to disability and functioning. Although the ICF domains may appear mutually exclusive, they often interact to create feedback loops which may be attributed to the complex nature of measuring stroke outcomes [82]. For instance, ischemic stroke may cause executive dysfunction and subsequent limitations in completing household activities (i.e., cooking and medication management) or engaging in work social activities in the community.

We categorized the assessments broadly with the ICF framework and found that most research examines disparities in the body functions domain. Although this focus contributes to our understanding of disparities in post-stroke disability and functioning, few studies have included assessments that examine personal and environmental factors important for contextualizing outcome differences. By including assessments that measure domains across the ICF, we may gain a more comprehensive understanding of racial/ethnic disparities in post-stroke disability.

We discovered a lack of consistency among the assessments used to examine post-stroke disability. The most frequently used tools were the FIM, mRS, and self- or proxy-report on abilities through national interview surveys. Although self-report type assessments are valuable in understanding disability, performance-based measures are inherently important when attempting to understand true-to-life disability, particularly among adults with stroke [83]. It was not surprising that the FIM appeared most frequently in our search as this tool is widely used in practice, particularly in inpatient rehabilitation, as it is a standard instrument for the Centers for Medicare and Medicaid Services (CMS). Additionally, the Uniform Data System for Medical Rehabilitation (UDSMR) incorporates this tool to examine racial/ethnic disparities in stroke outcomes and this may influence the frequency of FIM use [84].

Despite the projected growth in racial/ethnic representation, relatively few outcome measures have been validated among racial/ethnic populations that comprise the US [85]. 
Although some investigators have developed culturally tailored measures or separate normative data, this approach is limited in that differences in outcomes may remain unexplained and unexamined [85]. However, integrating assessments that are sensitive and conceptually relevant to unique cultures may support an enhanced understanding of disparities in post-stroke disability [86]. In general, the studies included in our review did not describe the validity of the selected instruments among the population of interest. In fact, it is possible, that the identified disparities in the literature are perpetuated by the outcome measures used. As the US becomes more diverse, it is essential that outcome assessments are validated with the same 'fervor' as used when examining other psychometric characteristics [86].

A striking finding in this review was the lack of representation among specific racial/ethnic groups in the US. As expected, we found that most studies have examined disparities in African Americans followed by Hispanics or Latinos then Asians. Interestingly, we found only one study that examined disparities among two specific populations: American Indian/ Alaska Native and Native Hawaiian/Pacific Islander. Examining disparities in both populations is important for several reasons. First, American Indians/Alaska Natives may have the highest stroke mortality rates among all US racial/ethnic groups with recent corrections of racial misclassification and non-representative sampling [87]. Most of the research on both American Indian/Alaska Native and Native Hawaiian/Pacific Islander have focused primarily on mortality rates, hospitalization, age, and comorbidity burden/risk. It is important to note that although several investigators examine disparities using a single population lens, this study aimed to examine outcome measures used with a comparative approach and other studies may exist among these populations that are not comparative in nature. Nonetheless, it is essential that future studies examine potential disparities in poststroke disability and functioning outcomes to support the elimination of health disparities among all racial/ethnic populations that comprise the US.

To mitigate disparities in post-stroke disability and functioning, it is crucial to understand underlying contributors across the time course of stroke recovery. Skolarus and Burke [17] describe four time points where differences in disability may arise: pre-stroke, acute stroke period, early stroke recovery period, and the community living/long-term outcome period. This is a noteworthy observation as differences in post-stroke disability may be viewed from a life course perspective where racial/ethnic differences in pre-stroke functioning and disability may have existed prior to the stroke. Additionally, across the time course of stroke recovery, outcomes may be influenced by a range of personal and environmental factors which are less studied and therefore not well-understood.

The majority of the studies we reviewed examined disparities in community living/long-term outcomes. However, we have determined the reasoning for the focus on disability in the context of the community is due to the nature of national data sets which are available for analysis to researchers. Several of the studies used survey methodology which may capture the lived experience post-stroke, but may not be adequate for capturing the complexities associated with post-stroke performance. Furthermore, few longitudinal studies have examined disparities by integrating performance-based measures that may capture true-tolife disability in the lived environment. We posit that future studies examining disparities in 
the context of the community integrate outcome measures that examine real-world contributors to disability through performance-based testing and examination of personal and environmental factors that may influence post-stroke disability outcomes.

\section{Limitations}

Despite a comprehensive search strategy, the primary limitation of this study is that we may have missed published articles that met inclusion criteria that did not emerge with our search strategy in the databases we selected. Additionally, this review only included studies that were comparative in nature and excluded studies that involved predictive modeling and qualitative research questions. The decision to limit the review to studies published in the US is another limitation; however, we made this decision as we expect that healthcare delivery systems likely influence outcome measures to some capacity. Lastly, it is noteworthy that some studies used outcome measures as stroke severity indicators and vice versa. For this study, we only included articles that explicitly identified each assessment as a contributor to overall disability and functioning versus a measure of stroke severity. However, this may have impacted our final assessment list and frequencies reported.

\section{Conclusions}

In research and practice, a wide variety of assessments can be used to examine post-stroke disability across the time course of stroke recovery. Several studies have identified disparities in functional outcomes; however, substantial problems abound from the identified assessments including a (1) lack of consistency in timing and type of outcome assessed and (2) lack of presented evidence of assessment validity among the targeted population. Moreover, representation amongst all US racial/ethnic groups, and emphasis on disparities in personal and environmental factors that contribute to disability are insufficient to draw inference. Additionally, few studies examine disability beyond 12-month outside of selfreported survey data. Although negative long-term outcomes may be attributed to aging or the presence of comorbidities, we urge researchers to further examine long-term disability outcomes in persons with stroke to better understand this problem. The key inference from this review is that future studies on disparities in post-stroke disability should consider integrating consistent use of similar assessments and a comprehensive disability framework as the lack of consistency complicates the identification and interpretation of racial/ethnic disparities across the time course of stroke recovery.

\section{Funding}

In accordance with Taylor \& Francis policy and our ethical obligations, the authors of this manuscript report that we receive funding from the American Heart Association (AHA) Grant [\#15SFDRN25870000, 15SFDRN24480016].

\section{References}

[1]. Ullberg T, Zia E, Petersson J, et al. Perceived unmet rehabilitation needs 1 year after stroke: an observational study from the Swedish stroke register. Stroke. 2016; 47:539-541. [PubMed: 26732564]

[2]. Patel MD, Tilling K, Lawrence E, et al. Relationships between long-term stroke disability, handicap and health-related quality of life. Age Ageing. 2006;35:273-279. [PubMed: 16638767] 
[3]. Walsh ME, Galvin R, Loughnane C, et al. Factors associated with community reintegration in the first year after stroke: a qualitative meta-synthesis. Disabil Rehabil. 2015;37: 1599-1608. [PubMed: 25382215]

[4]. Ellis C, Boan AD, Turan TN, et al. Racial differences in post-stroke rehabilitation utilization and functional outcomes. Arch Phys Med Rehabil. 2015;96:84-90. [PubMed: 25223490]

[5]. Skolarus LE, Wing JJ, Morgenstern LB, et al. Mexican Americans are less likely to return to work following stroke: clinical and policy implications. J Stroke Cerebrovasc Dis. 2016;25:1851-1855. [PubMed: 27132488]

[6]. Lisabeth LD, Sanchez BN, Baek J, et al. Neurological, functional, and cognitive stroke outcomes in Mexican Americans. Stroke. 2014;45:1096-1101. [PubMed: 24627112]

[7]. Roth DL, Dhamoon MS. Racial disparities in long-termstroke outcomes: evidence from nationwide epidemiologic studies. Neurology. 2014;83:384-385. [PubMed: 24975861]

[8]. Burke JF, Freedman VA, Lisabeth LD, et al. Racial differences in disability after stroke: results from a nationwide study. Neurology. 2014;83:390-397. [PubMed: 24975857]

[9]. World Health Organization. How to use the ICF: a practical manual for using the international classification of functioning, disability and health (ICF). Geneva (CH); 2013.

[10]. World Health Organization. International classification of functioning, disability and health: ICF [Internet]. World Health Organization; 2002 Available from: http://www.who.int/ classifications/icf/icfbeginnersguide.pdf?ua=1

[11]. World Health Organization. International classification of impairments, disabilities, and handicaps: a manual of classificationrelating to the consequences of disease. Geneva $(\mathrm{CH})$ : WHO Publications; 1980.

[12]. de Kleijn-de Vrankrijker MW. The long way from the International Classification of Impairments, Disabilities and Handicaps (ICIDH) to the International Classification of Functioning, Disability and Health (ICF). Disabil Rehabil. 2003;25:561-564. [PubMed: 12959328]

[13]. Duncan PW, Jorgensen HS, Wade DT. Outcome measures in acute stroke trials: a systematic review and some recommendations to improve practice. Stroke 2000;31:1429-1438. [PubMed: 10835468]

[14]. Colquhoun HL, Levac D, O’Brien KK, et al. Scoping reviews: time for clarity in definition, methods, and reporting. J Clin Epidemiol. 2014;67:1291-1294. [PubMed: 25034198]

[15]. Richesson R, Anderson M, Smerek M. Race/ethnicity data standard from the NIH collaborator phenotypes, data standards, and data quality core [Internet]. NIH Collaboratory; 2014 Available from: https://www.nihcollaboratory.org/Products/RaceEthnicity_standard.pdf. Accessed August 22, 2017.

[16]. Revisions to the standards for the classification of federal data on race and ethnicity [Internet]. Washington (DC): Office of Management and Budget; 1997 Available from: https:// www.whitehouse.gov/omb/

[17]. Skolarus LE, Burke JF. Towards an understanding of racial differences in post-stroke disability. Curr Epidemiol Rep. 2015;2:191-196. [PubMed: 26525431]

[18]. Keith RA, Granger CV, Hamilton BB, et al. The functional independence measure: a new tool for rehabilitation. Adv Clin Rehabil. 1987;1:6-18. [PubMed: 3503663]

[19]. Berges IM, Kuo YF, Ottenbacher KJ, et al. Recovery of functional status after stroke in a triethnic population. PM R. 2012;4:290-295. [PubMed: 22541375]

[20]. Bhandari VK, Kushel M, Price L, et al. Racial disparities in outcomes of inpatient stroke rehabilitation. Arch Phys Med Rehabil. 2005;86:2081-2086. [PubMed: 16271552]

[21]. Cavanagh S, Hogan K, Fairfax J. Assessing cognitive function after stroke using the FIM instrument. J Neurosci Nurs. 2002;34:99.

[22]. Chiou-Tan FY, Keng MJ, Graves DE, et al. Racial/ethnic differences in FIM scores and length of stay for underinsured patients undergoing stroke inpatient rehabilitation. Am J Phys Med Rehabil. 2006;85:415-423. [PubMed: 16628148]

[23]. Deutscher D, Horn SD, Smout RJ, et al. Black-white disparities in motor function outcomes taking into account patient characteristics, nontherapy ancillaries, therapy activities, and therapy interventions. Arch Phys Med Rehabil. 2010;91:1722-1730. [PubMed: 21044717] 
[24]. Hinojosa MS, Rittman M, Hinojosa R, et al. Racial/ethnic variation in recovery of motor function in stroke survivors: role of informal caregivers. J Rehabil Res Dev. 2009;46:223-232. [PubMed: 19533536]

[25]. Horn SD, Deutscher D, Smout RJ, et al. Black-white differences in patient characteristics, treatments, and outcomes in inpatient stroke rehabilitation. Arch Phys Med Rehabil. 2010;91:1712-1721. [PubMed: 21044716]

[26]. Ottenbacher KJ, Campbell J, Kuo YF, et al. Racial and ethnic differences in postacute rehabilitation outcomes after stroke in the united states. Stroke. 2008;39:1514-1519. [PubMed: 18340094]

[27]. Perrin PB, Heesacker M, Uthe CE, et al. Caregiver mental health and racial/ethnic disparities in stroke: implications for culturally sensitive interventions. Rehabil Psychol. 2010;55:372-382. [PubMed: 21171796]

[28]. Rabadi MH, Rabadi FM, Hallford G, et al. Does race influence functional outcomes in patients with acute stroke undergoing inpatient rehabilitation? Am J Phys Med Rehabil. 2012;91:375382. [PubMed: 22311058]

[29]. Putman K, Horn S, Smout R, et al. Racial disparities in stroke functional outcomes upon discharge from inpatient rehabilitation facilities. Disabil Rehabil. 2010;32:1604-1611. [PubMed: 20158376]

[30]. Katz S. Assessing self-maintenance: activities of daily living, mobility, and instrumental activities of daily living. J Am Geriatr Soc. 1983;31:721-727. [PubMed: 6418786]

[31]. Boyington JEA, Howard DL, Holmes DN. Self-rated health, activities of daily living, and mobility limitations among black and white stroke survivors. J Aging Health. 2008;20:920-939. [PubMed: 18836032]

[32]. Granger CV, Albrecht GL, Hamilton BB. Outcome of comprehensive medical rehabilitation: measurement by PULSES profile and the Barthel Index. Arch Phys Med Rehabil. 1979;60:145154. [PubMed: 157729]

[33]. Horner RD, Swanson JW, Bosworth HB, et al. Effects of race and poverty on the process and outcome of inpatient rehabilitation services among stroke patients. Stroke. 2003;34:1027-1031. [PubMed: 12624220]

[34]. Roth DL, Haley WE, Clay OJ, et al. Race and gender differences in 1-year outcomes for community-dwelling stroke survivors with family caregivers. Stroke. 2011;42:626-631. [PubMed: 21257820]

[35]. Schuling J, de Haan R, Limburg M, et al. The Frenchay Activities Index. assessment of functional status in stroke patients. Stroke. 1993;24:1173-1177. [PubMed: 8342192]

[36]. Hinojosa R, Haun J, Hinojosa MS, et al. Social isolation post-stroke: relationship between race/ ethnicity, depression, and functional independence. Top Stroke Rehabil. 2011;18:79-86. [PubMed: 21371987]

[37]. Rankin J. Cerebral vascular accidents in patients over the age of 60. II. Prognosis. Scott Med J. 1957;2:200-215. [PubMed: 13432835]

[38]. Mandava P, Murthy SB, Munoz M, et al. Explicit consideration of baseline factors to assess recombinant tissue-type plasminogen activator response with respect to race and sex. Stroke. 2013;44:1525-1531. [PubMed: 23674524]

[39]. Boehme AK, Siegler JE, Mullen MT, et al. Racial and gender differences in stroke severity, outcomes, and treatment in patients with acute ischemic stroke. J Stroke Cerebrovasc Dis. 2014;23:255-261.

[40]. Neil WP, Raman R, Hemmen TM, et al. Association of Hispanic ethnicity with acute ischemic stroke care processes and outcomes. Ethn Dis. 2015;25:19-23. [PubMed: 25812247]

[41]. Tsivgoulis G, Putaala J, Sharma VK, et al. Racial disparities in early mortality in 1,134 young patients with acute stroke. Neurol Sci. 2014;35:1041-1049. [PubMed: 24469348]

[42]. Jennett B, Snoek J, Bond MR, et al. Disability after severe head injury: observations on the use of the Glasgow Outcome Scale. J Neurol Neurosurg Psychiatry. 1981;44:285-293. [PubMed: 6453957] 
[43]. Rosen D, Novakovic R, Goldenberg FD, et al. Racial differences in demographics, acute complications, and outcomes in patients with subarachnoid hemorrhage: a large patient series. J Neurosurg. 2005;103:18-24. [PubMed: 16121968]

[44]. Burke JF, Skolarus LE, Freedman VA. Racial disparities in poststroke activity limitations are not due to differences in prestroke activity limitation. J Stroke Cerebrovasc Dis. 2015;24:1636-1639. [PubMed: 26026217]

[45]. Capistrant BD, Mejia NI, Liu SY, et al. The disability burden associated with stroke emerges before stroke onset and differentially affects blacks: results from the health and retirement study cohort. J Gerontol Ser A Biol Sci Med Sci. 2014;69:860-870. [PubMed: 24444610]

[46]. Ellis C, Grubaugh AL, Egede LE. Factors associated with SF-12 physical and mental health quality of life scores in adults with stroke. J Stroke Cerebrovasc Dis. 2013;22:309-317. [PubMed: 22005038]

[47]. Kroenke K, Spitzer RL, Williams JBW. The PHQ-9: validity of a brief depression severity measure. J Gen Intern Med. 2001;16:606-613. [PubMed: 11556941]

[48]. Skolarus LE, Lisabeth LD, Sanchez BN, et al. The prevalence of spirituality, optimism, depression, and fatalism in a biethnic stroke population. J Relig Health. 2012;51:1293-1305. [PubMed: 21184281]

[49]. Spitzer RL, Kroenke K, Williams JBW, et al. A brief measure for assessing generalized anxiety disorder. Arch Intern Med. 2006;166:1092. [PubMed: 16717171]

[50]. Lewis SC, Dennis MS, O’Rourke SJ, et al. Negative attitudes among short-term stroke survivors predict worse long-term survival. Stroke. 2001;32:1640-1645. [PubMed: 11441213]

[51]. Kessler RC, Andrews G, Colpe LJ, et al. Short screening scales to monitor population prevalences and trends in non-specific psychological distress. Psychol Med. 2002;32:959-976. [PubMed: 12214795]

[52]. Skolarus LE, Lisabeth LD, Burke JF, et al. Racial and ethnic differences in mental distress among stroke survivors. Ethn Dis. 2015;25:138-144. [PubMed: 26118139]

[53]. Kertesz A. The western aphasia battery Andrew Kertesz The Western Aphasia Battery. New York: Grune and Stratton; 1982.

[54]. Ellis C, Peach RK. Racial-ethnic differences in word fluency and auditory comprehension among persons with poststroke aphasia. Arch Phys Med Rehabil. 2017;98: 681-686. [PubMed: 27840130]

[55]. Skolarus LE, Freedman VA, Feng C, et al. African American stroke survivors: more caregiving time, but less caregiving burden. Circ Cardiovasc Qual Outcomes. 2017;10:1-6.

[56]. Wang Q, Mej_\{a-Guevara I, Rist PM, et al. Changes in memory before and after stroke differ by age and sex, but not by race. Cerebrovasc Dis. 2014;37:235-243. [PubMed: 24686293]

[57]. Freedman M, Leach L, Kaplan E, et al. Clock drawing: a neuropsychological analysis. New York: Oxford University Press, Inc.; 1994.

[58]. Folstein MF, Folstein SE, McHugh PR. Mini-mental state. A practical method for grading the cognitive state of patients for the clinician. J Psychiatr Res. 1975;12:189-198. [PubMed: 1202204]

[59]. Brandt J, Spencer M, Folstein M (1988). The telephone interview for cognitive status. Neuropsychiatry Neuropsychol Behav Neurol. 1, 111-117.

[60]. Levine DA, Kabeto M, Langa KM et al., Does stroke contribute to racial differences in cognitive decline? Stroke. 2015;46:1897-1902. [PubMed: 25999389]

[61]. Gershon RC, Wagster MV, Hendrie HC, et al. NIH toolbox for assessment of neurological and behavioral function. Neurology. 2013;80:S2-S6. [PubMed: 23479538]

[62]. Johnson NX, Marquine MJ, Flores I, et al. Racial differences in neurocognitive outcomes poststroke: the impact of healthcare variables. J Int Neuropsychol Soc. 2017;23:640-652. [PubMed: 28660849]

[63]. Jorm AF, Jacomb PA. The Informant Questionnaire on Cognitive Decline in the Elderly (IQCODE): socio-demographic correlates, reliability, validity and some norms. Psychol Med. 1989;19:1015. [PubMed: 2594878]

[64]. Collin C, Wade D. Assessing motor impairment after stroke: a pilot reliability study. J Neurol Neurosurg Psychiatry. 1990;53:576-579. [PubMed: 2391521] 
[65]. Stewart D, Burns J, Dunn S, et al. The two-minute walking test: a sensitive index of mobility in the rehabilitation of elderly patients. Clin Rehabil. 1990;4:273-276.

[66]. Enright PL. The six-minute walk test. Respir Care. 2003;48:783-785. [PubMed: 12890299]

[67]. Hinson HE, Patterson SL, Macko RF, et al. Reduced cardiovascular fitness and ambulatory function in black and white stroke survivors. Ethn Dis. 2007;17:682-685. [PubMed: 18072379]

[68]. Serra MC, Hafer-Macko CE, Ivey FM, et al. Impact of serum nutritional status on physical function in African American and Caucasian stroke survivors 2014. Stroke Res Treat. $2014 ; 74308$.

[69]. Brott T, Adams HP, Olinger CP, et al. Measurements of acute cerebral infarction: a clinical examination scale. Stroke. 1989;20:864-870. [PubMed: 2749846]

[70]. Xian Y, Holloway RG, Smith EE, et al. Racial/ethnic differences in process of care and outcomes among patients hospitalized with intracerebral hemorrhage. Stroke. 2014;45: 3243-3250. [PubMed: 25213344]

[71]. Centers for Disease Control and Prevention. Differences in disability among black and white stroke survivors - United States, 2000-2001. Morb Mortal Wkly Rep. 2005;54:3-6.

[72]. Ellis C, Magwood G, White B. Racial differences in patient reported post-stroke disability in older adults. Geriatrics. 2017;2:1-9.

[73]. McHorney CA, Ware JEJ, Rachel Lu JF, et al. The MOS 36-Item Short-Form Health Survey (SF-36): III. tests of data quality, scaling assumptions, and reliability across diverse patient groups. Med Care. 1994;32:40-66. [PubMed: 8277801]

[74]. Williams LS, Weinberger M, Harris LE, et al. Development of a stroke-specific quality of life scale. Stroke. 1999;30: 1362-1369. [PubMed: 10390308]

[75]. Reeves SL, Brown DL, Baek J, et al. Ethnic differences in poststroke quality of life in the brain attack surveillance in Corpus Christi (BASIC) project. Stroke. 2015;46:2896-2901. [PubMed: 26286542]

[76]. Scheier MF, Carver CS, Bridges MW. Distinguishing optimism from neuroticism (and trait anxiety, self-mastery, and self-esteem): a reevaluation of the Life Orientation Test. J Pers Soc Psychol. 1994;67:1063-1078. [PubMed: 7815302]

[77]. Pearlin LI, Schooler C. The structure of coping. J Health Soc Behav. 1978;19:2-21. [PubMed: 649936]

[78]. Yesavage JA, Brink TL, Rose TL, et al. Development and validation of the geriatric depression screening scale: a preliminary report. J Psychiatr Res. 1982;17:37-49. [PubMed: 7183759]

[79]. Radloff LS. The CES-D scale: a self-report depression scale for research in the general population. Appl Psychol Meas. 1977;1:385-401.

[80]. Goldmann E, Roberts ET, Parikh NS, et al. Race/ethnic differences in post-stroke depression (PSD): findings from the stroke warning to examine race/ethnic differences in information and faster treatment (SWIFT) study. Ethn Dis. 2016;26:1-8. [PubMed: 26843790]

[81]. Duncan PW, Wallace D, Lai SM, et al. The stroke impact scale version 2.0: evaluation of reliability, validity, and sensitivity to change. Stroke. 1999;30:2131-2140. [PubMed: 10512918]

[82]. Harrison JK, McArthur KS, Quinn TJ. Assessment scales in stroke: clinimetric and clinical considerations. Clin Interv Aging. 2013;8:201-211. [PubMed: 23440256]

[83]. Burns SC, Neville M. Cognitive assessment trends in home health care for adults with mild stroke. Am J Occup Ther. 2016;70:1-8.

[84]. Fiedler RC, Granger CV The functional independence measure: a measurement of disability and medical rehabilitation In: Chino N, Melvin JL, editors. Functional evaluation of stroke patients. Tokyo: Springer; 1996.

[85]. Manly JJ. Deconstructing race and ethnicity: implications for measurement of health outcomes. Med Care. 2006;44:S10-S16. [PubMed: 17060816]

[86]. Victorson D, Manly J, Wallner-Allen K, et al. Using the NIH Toolbox in special populations: considerations for assessment of pediatric, geriatric, culturally diverse, non-English speaking, and disabled individuals. Neurology. 2013;80:S13-S19.

[87]. Harris R, Nelson LA, Muller C, et al. Stroke in American Indians and Alaska Natives: a systematic review. Am J Public Health. 2015;105:e16-e26. 


\section{IMPLICATIONS FOR REHABILITATION}

- An enhanced understanding of racial/ethnic disparities in post-stroke disability outcomes is inherently important among rehabilitation practitioners who frequently engage with racial/ethnic minority populations across the time course of stroke recovery.

- Clinicians should carefully consider the psychometric properties of assessment tools to counter potential racial bias.

- Clinicians should be aware that many assessments used in stroke rehabilitation lack cultural sensitivity and could result in inaccurate assessment findings. 


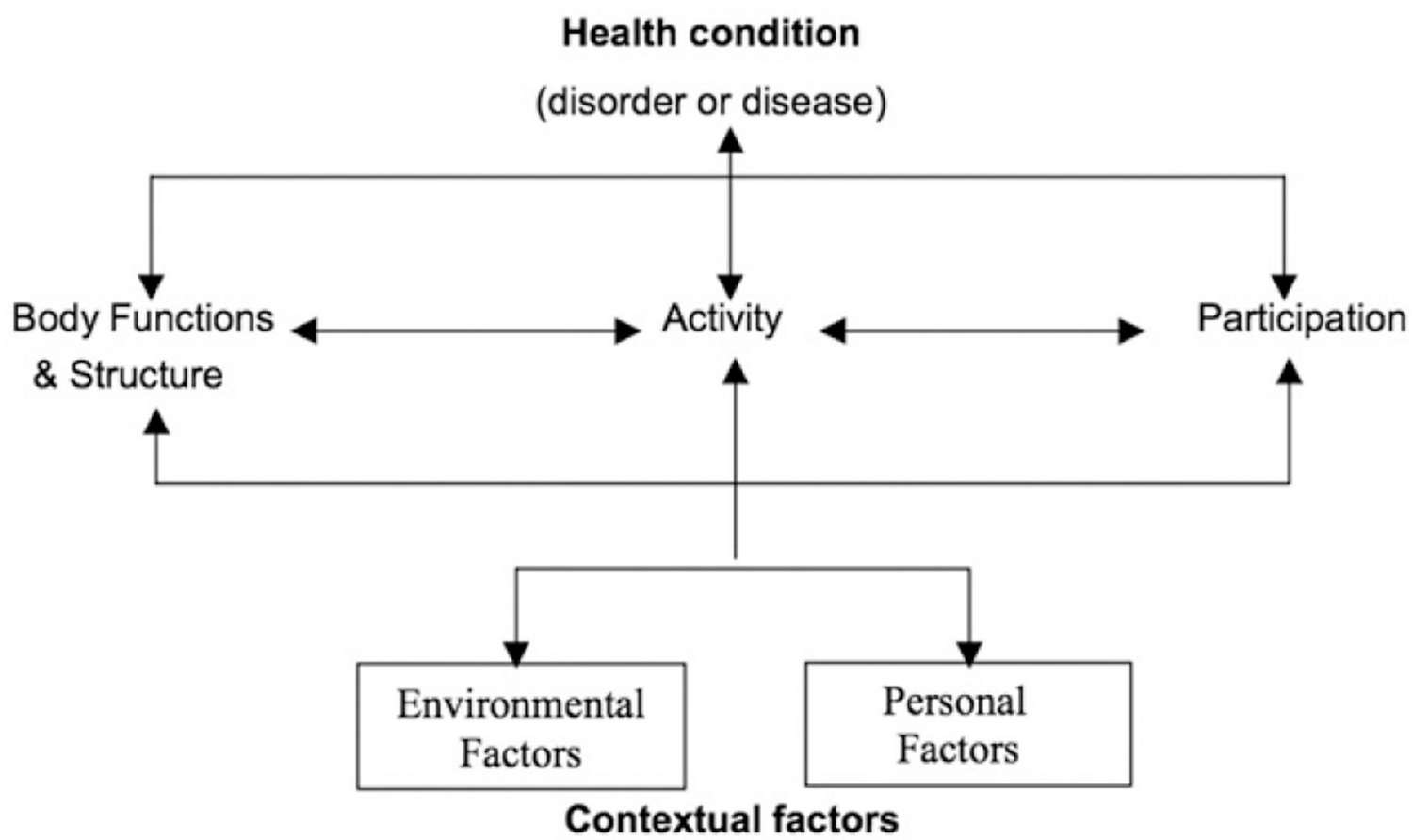

Figure 1.

International classification of functioning, disability and health. Note: Reprinted from World Health Organization, Geneva, Towards a Common Language for Functioning, Disability, and Health ICF, Page 9, Copyright 2002. 
Records identified through database searching ( $n=1,465$ )
Additional records identified through hand-searching other sources $(n=326)$

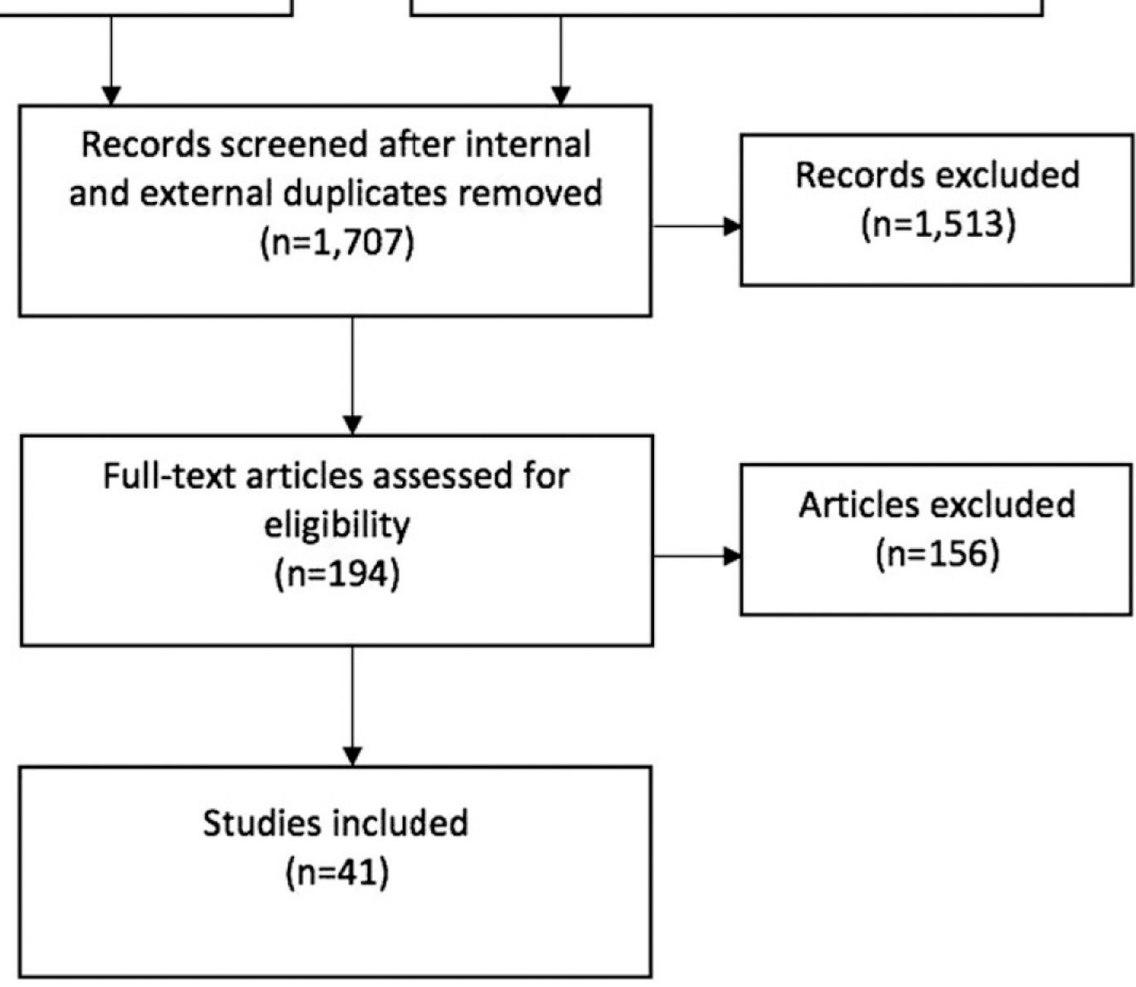

Figure 2.

Decision making process for study inclusion. 


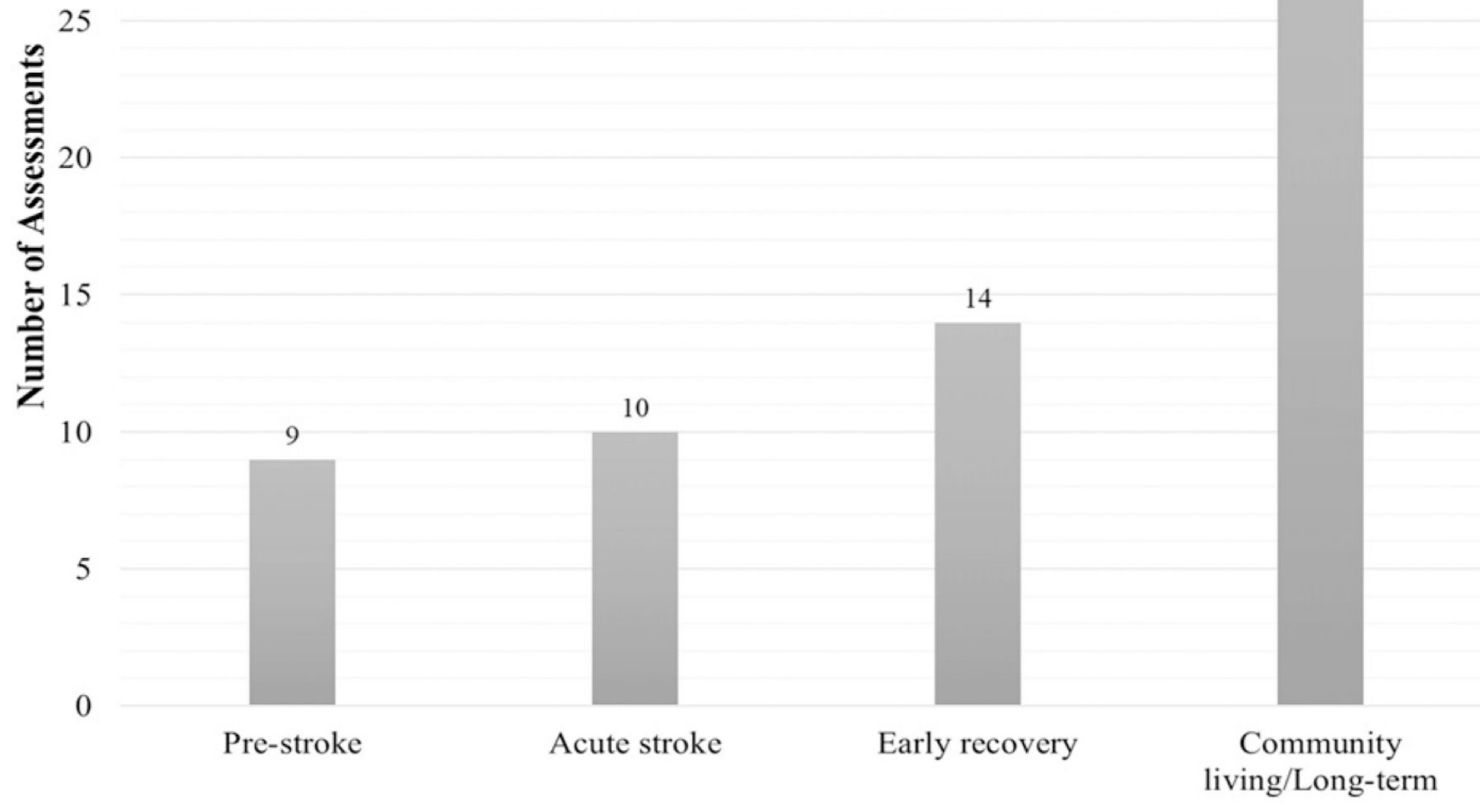

\section{Time Point}

Figure 3.

Outcomes measured across the time course of stroke recovery. 
45

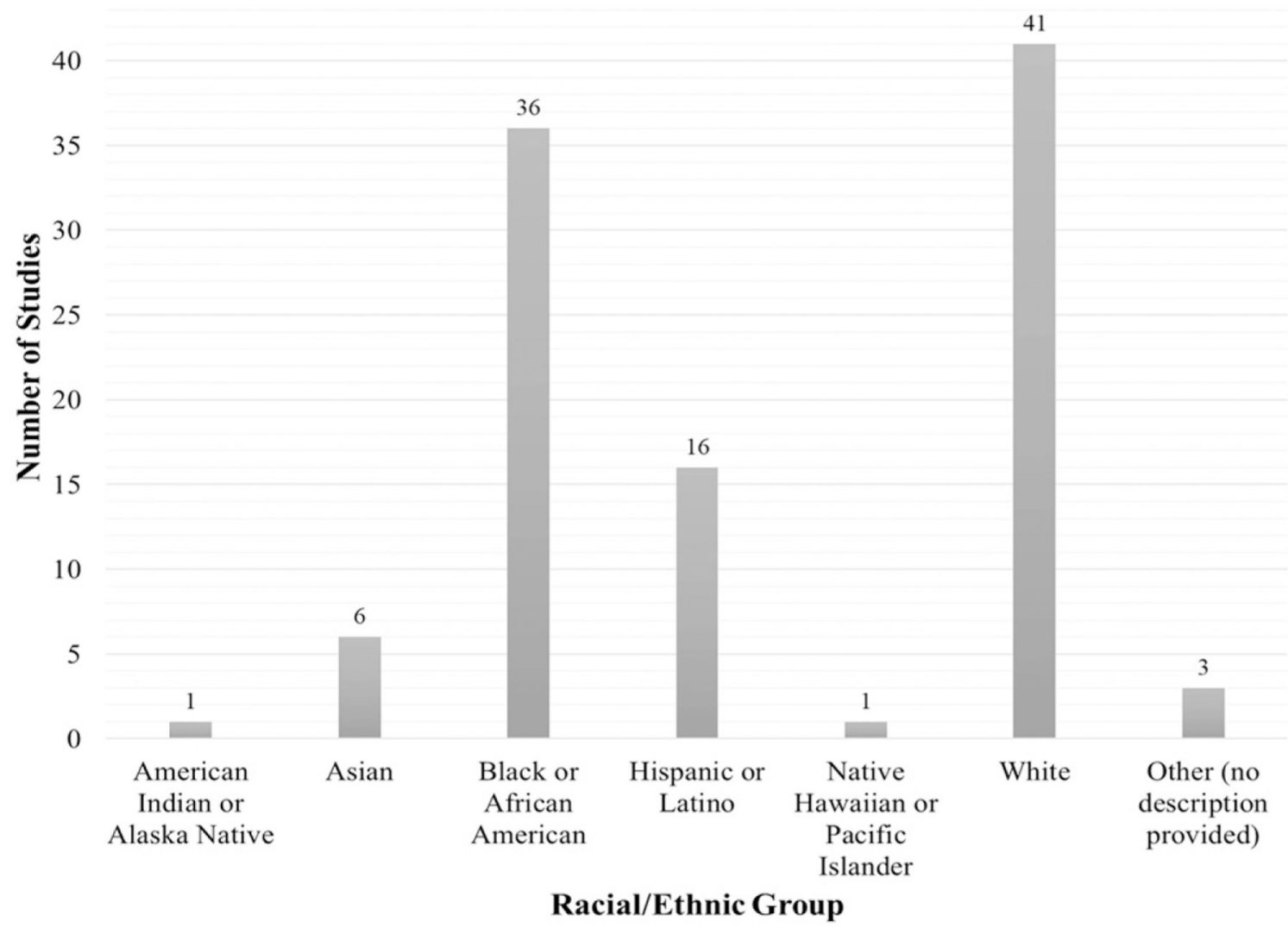

Figure 4.

Racial/ethnic representation within the included studies. 


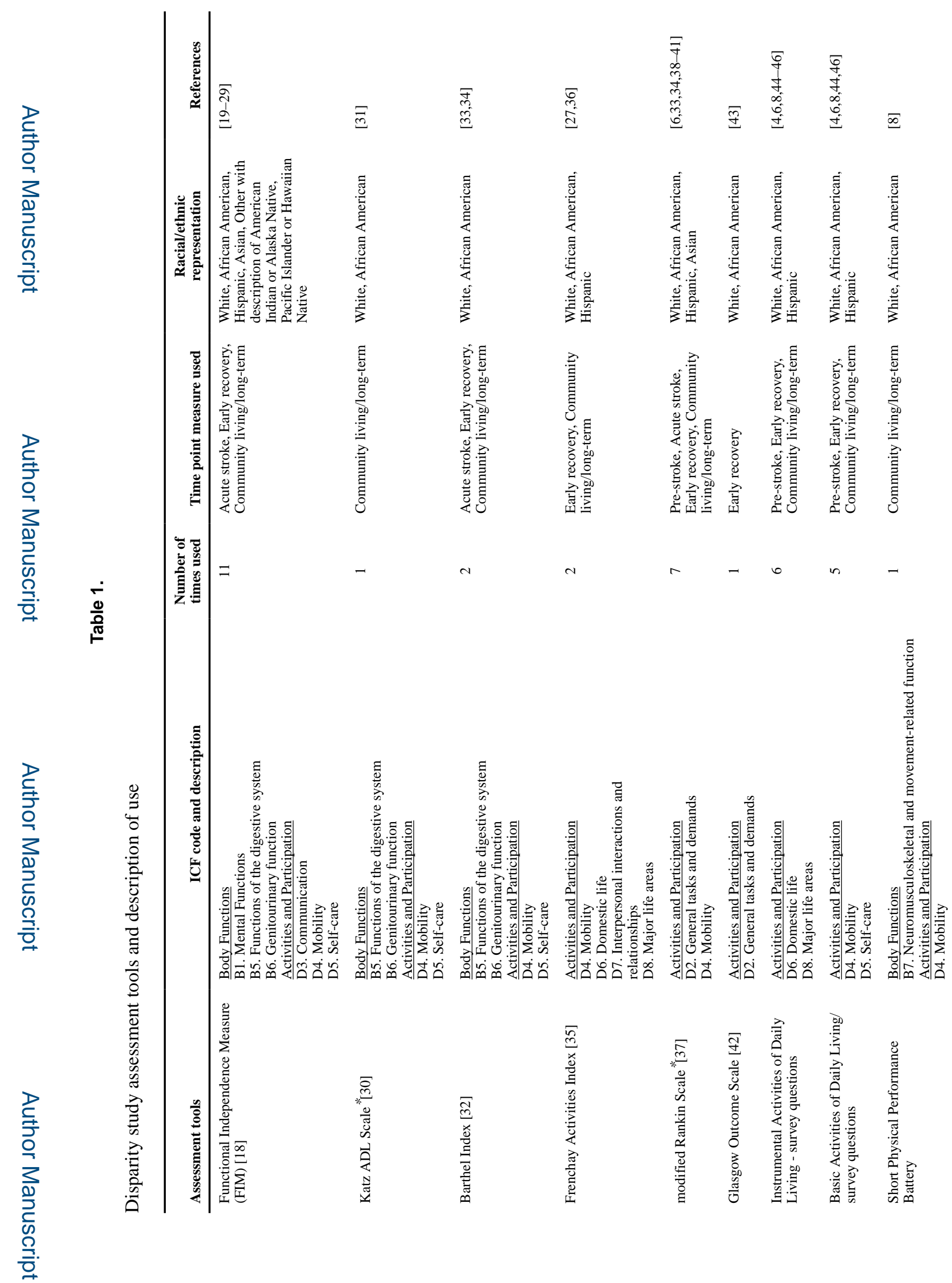

Disabil Rehabil. Author manuscript; available in PMC 2020 April 14. 
Burns et al.

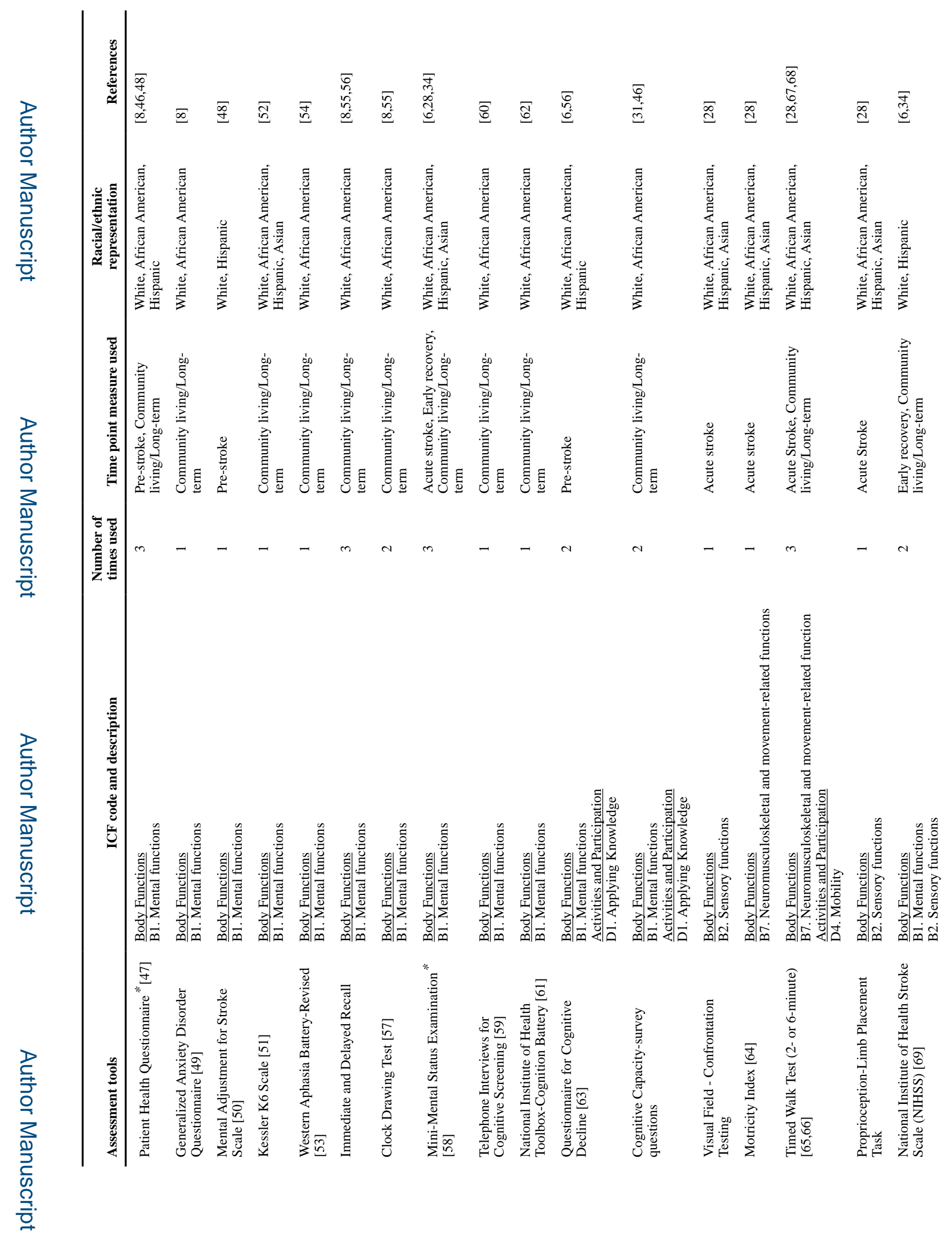

Disabil Rehabil. Author manuscript; available in PMC 2020 April 14. 
Burns et al.

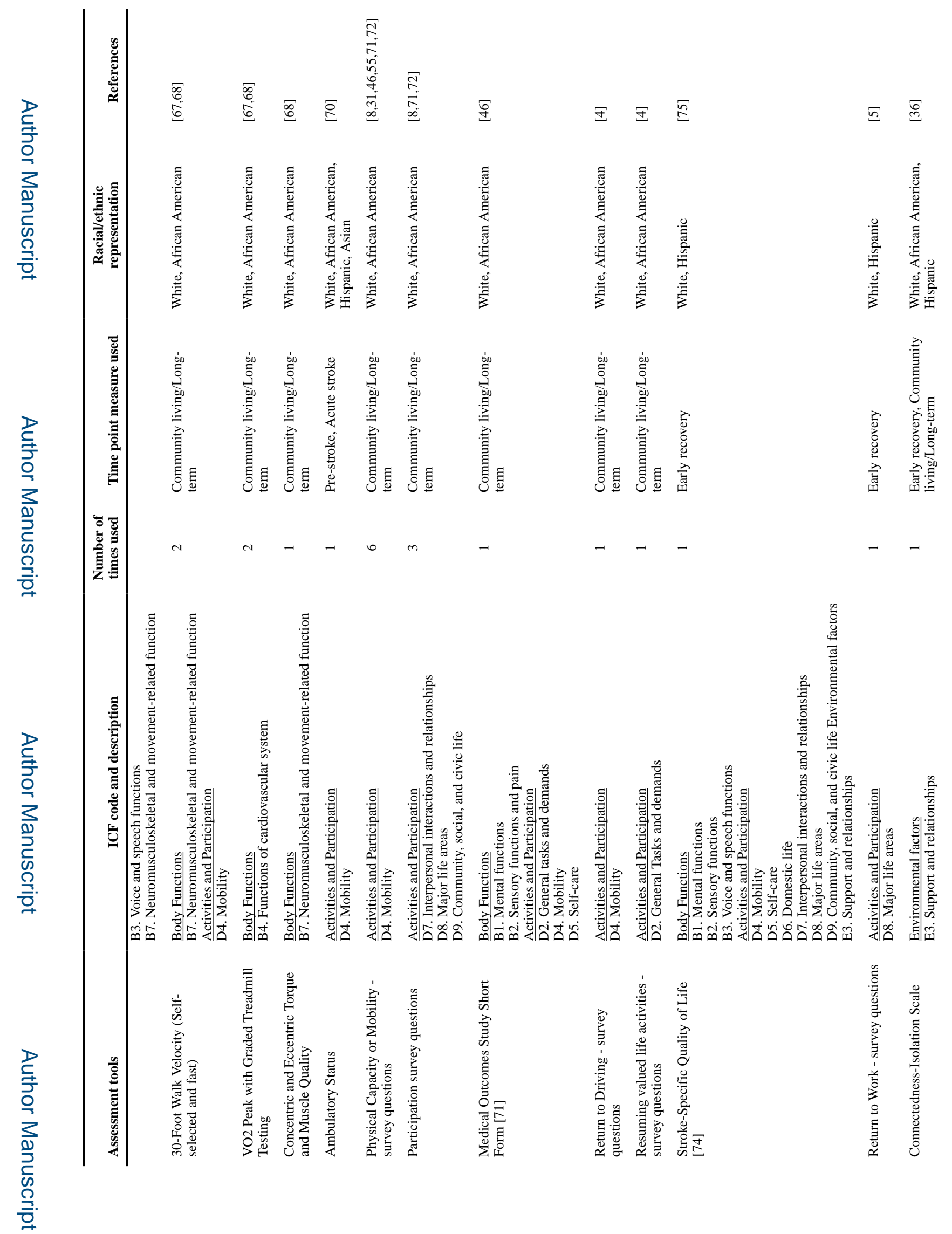

Disabil Rehabil. Author manuscript; available in PMC 2020 April 14. 
Burns et al.

Page 20

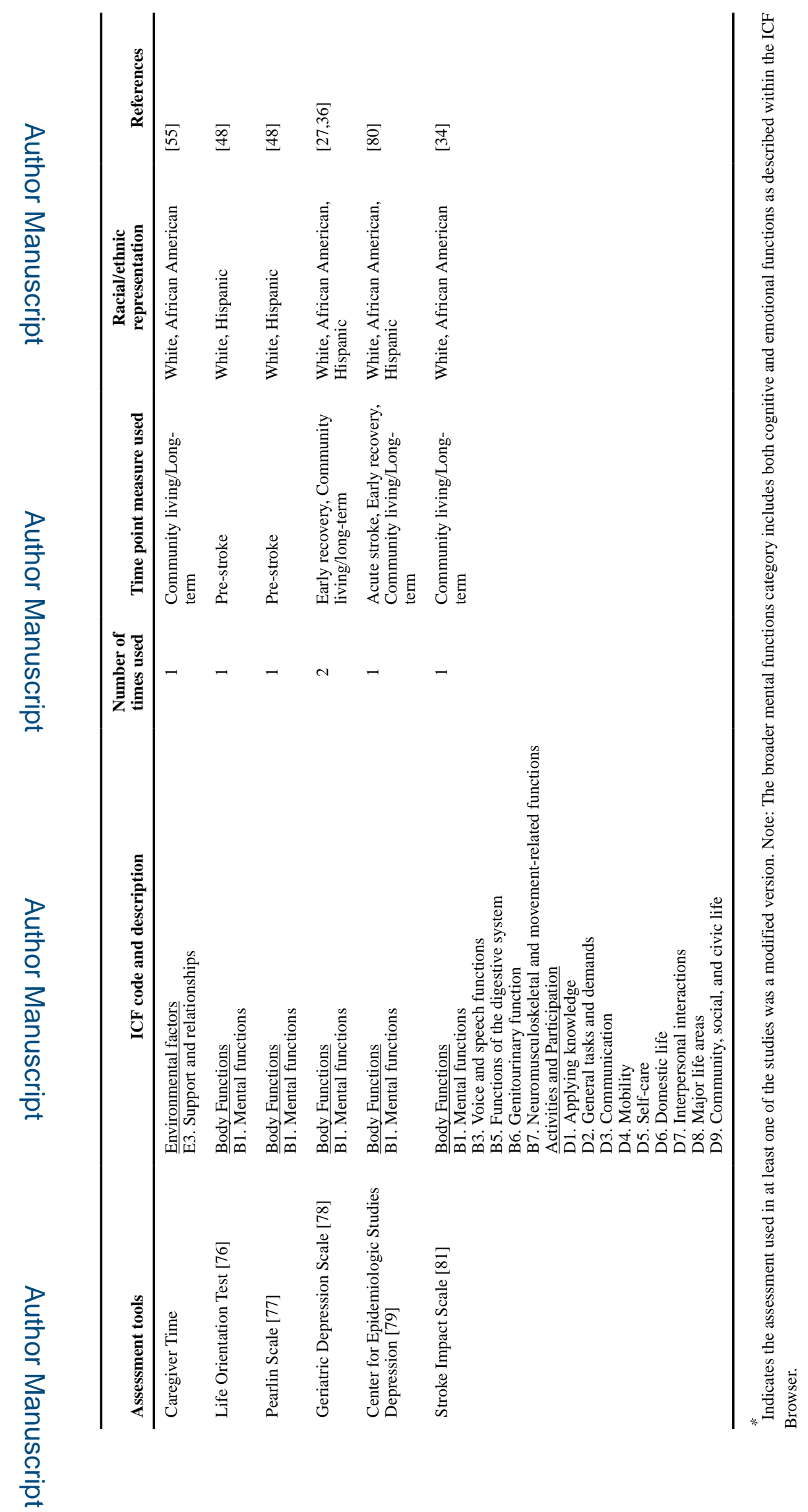

Disabil Rehabil. Author manuscript; available in PMC 2020 April 14. 